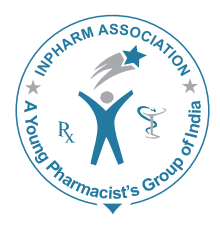

\title{
Treating Tuberculosis: Time to Introduce Fixed-Dose Drug Combinations
}

Tuberculosis has been an elusive infectious disease. In India, two deaths occur every three minutes due to tuberculosis. ${ }^{[1]}$ As modern antituberculosis therapy (ATT) can cure all patients, these deaths can be prevented. But it is imperative that these patients take ATT for the prescribed duration (minimum of six months). Hence, adherence to treatment plays an important role in the success of the treatment.

\section{TREATMENT STRATEGY}

The Revised National Tuberculosis Control Programme (RNTCP) of India is based on Directly Observed TreatmentShort course (DOTS) strategy. The RNTCP was launched as a national program in 1997 and the entire country was covered under DOTS by March 2006. ${ }^{[1]}$ Even though the treatment is directly observed, there are defaulters under this strategy too. This is of concern as it can lead to the serious issue of multidrug-resistant tuberculosis (MDR TB).

\section{RESOLVED ISSUES}

Adherence to treatment is a keystone in the success of the program. The factors affecting adherence can be grouped as patient factors, disease factors, and medication characteristics. A few of the factors hindering the success were identified and rectified in the recent past.

Simplifying the regimen

Earlier, there were five categories of treatment for

\begin{tabular}{|l|l|}
\hline \multicolumn{2}{|c|}{ Access this article online } \\
\hline Quick Response Code: & \\
\hline & Website: \\
\hline & www.jyoungpharm.in \\
& \\
\hline
\end{tabular}

tuberculosis and this made the regimen complex. In 2011, this regimen has been simplified by RNTCP to include only two categories [Table 1]. ${ }^{[2]}$ This simplified regimen has reduced the logistic difficulties in introducing fixed-dose drug combinations (FDCs) into the regimen.

\section{Improvised formulation technology}

In the early 1990s, FDCs of antitubercular drugs were not advocated because of their relatively poor bioavailability and short shelf life. ${ }^{[3]}$ With the present improved formulation technologies, the currently available FDCs are bioequivalent to single drug reference products. Moreover, the stability of these FDCs even after six months in tropical countries is well established. ${ }^{[3]}$ Randomized controlled trials have proved their efficacy and systematic reviews also favor the use of FDCs for tuberculosis. ${ }^{[3,4]}$

\section{UNRESOLVED PROBLEMS}

\section{Pill burden}

Presently, a category I tuberculosis patient should take six tablets and one capsule (two tablets each of isoniazid, pyrazinamide, and ethambutol, and one capsule of

Table 1: Revised categories of treatment for tuberculosis

\begin{tabular}{|c|c|c|c|}
\hline \multirow{2}{*}{$\begin{array}{l}\text { Treatment } \\
\text { group }\end{array}$} & \multirow[t]{2}{*}{ Type of patient } & \multicolumn{2}{|c|}{ Regimens } \\
\hline & & $\begin{array}{c}\text { Intensive } \\
\text { phase }\end{array}$ & $\begin{array}{c}\text { Continuation } \\
\text { phase }\end{array}$ \\
\hline $\begin{array}{l}\text { New } \\
\text { (category I) }\end{array}$ & $\begin{array}{l}\text { New sputum smear-positive } \\
\text { New sputum smear-negative } \\
\text { New extrapulmonary } \\
\text { New others }\end{array}$ & $2 \mathrm{H}_{3} \mathrm{R}_{3} \mathrm{Z}_{3} \mathrm{E}_{3}$ & $4 \mathrm{H}_{3} \mathrm{R}_{3}$ \\
\hline $\begin{array}{l}\text { Previously } \\
\text { treated } \\
\text { (category II) }\end{array}$ & $\begin{array}{l}\text { Smear-positive relapse } \\
\text { Smear-positive failure } \\
\text { Smear-positive treatment } \\
\text { after default } \\
\text { Others }\end{array}$ & $\begin{array}{c}2 \mathrm{H}_{3} \mathrm{R}_{3} \mathrm{Z}_{3} \mathrm{E}_{3} \mathrm{~S}_{3}+ \\
1 \mathrm{H}_{3} \mathrm{R}_{3} \mathrm{Z}_{3} \mathrm{E}_{3}\end{array}$ & $5 \mathrm{H}_{3} \mathrm{R}_{3} \mathrm{E}_{3}$ \\
\hline
\end{tabular}




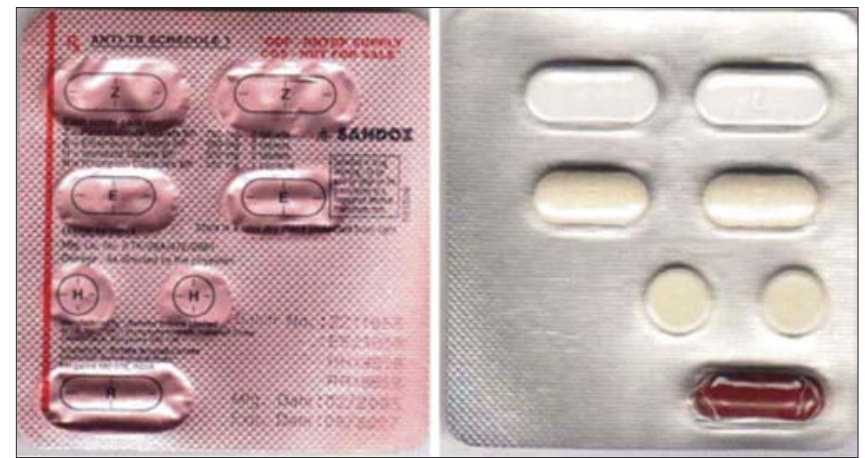

Figure 1: Combination pack of intensive phase category I for the treatment of tuberculosis

rifampicin) available as a combination pack for a single-day treatment [Figure 1]. Even though DOTS is an effective strategy to improve compliance, the pill burden of the current regimen hinders compliance and, thereby, the success of the treatment.

\section{Discrepancy between guidelines and regimens}

Standard 8 of International Standards for Tuberculosis Care and the WHO Guidelines for Treatment of Tuberculosis recommend the use of FDCs for the treatment of tuberculosis. ${ }^{[2,5]}$ However, the regimens followed by RNTCP under the DOTS strategy have not yet incorporated this recommendation.

\section{THE SOLUTION}

Introducing FDCs for the treatment of tuberculosis seems to be a promising solution to the problem. Incorporating FDCs into the present regimen would offer the following benefits:

- The pill burden is drastically reduced, thereby increasing acceptability by the patient.
- Selection of a particular drug from the combination pack and the consequent monotherapy leading to the development of drug-resistant forms can be reduced.

- Logistic difficulties such as ordering, storage, handling, and delivery of the drug can be reduced by FDCs.

Moreover, FDCs of antitubercular drugs are readily available in the market and private practitioners are using them. When we have allowed hundreds of irrational FDCs to creep into the market, why should we hesitate to introduce a rational FDC into our national program? It's right time that we introduced FDCs into the RNTCPDOTS regimen for the treatment of tuberculosis.

\section{Manikandan S}

Department of Pharmacology, Jawaharlal Institute of Postgraduate Medical Education and Research (JIPMER),

Pondicherry, India. E-mail: drsmanikandan001@gmail.com

\section{REFERENCES}

1. TBC India [Home page on internet]. Available from: http://www.tbcindia. nic.in/key.html. [Last accessed on 2012 Oct 12].

2. RNTCP Annual Report 2011. Available from: http://www.tbcindia.nic.in/ documents.html. [Last accessed on 2012 Oct 12].

3. Monedero I, Caminero JA. Evidence for promoting fixed dose combination drugs in tuberculosis treatment and control: A review. Int J Tuberc Lung Dis 2011;15:433-9.

4. Lienhardt C, Cook SV, Burgos M, Yorke-Edwards V, Rigouts L, Anyo G, et al. Efficacy and safety of a 4-drug fixed-dose combination regimen compared with separate drugs for treatment of pulmonary tuberculosis: The Study C randomized controlled trial. JAMA 2011;305:1415-23.

5. WHO Guidelines on tuberculosis. Available from: http://www.who.int/ publications/guidelines/tuberculosis/en/index.html. [Last accessed on 2012 Oct 12].

How to cite this article: Manikandan S. Treating tuberculosis: Time to Introduce fixed-dose drug combinations. J Young Pharmacists 2012;4:199-200. 